\title{
44
}

Rupantaran : A Multidisciplinary Journal

Vol. IV : pp 44-51, October, 2020

ISSN : 2091-0061

https://doi.org/10.3126/rupantaran.v4i1.34016

Research Management Cell (RMC)

Dhankuta Multiple Campus, Dhankuta

Tribhuvan University, Nepal

\section{Corona Virus Disease 2019 (COVID-19) Prevention and Control Measures in Community: A Literature Review}

\author{
Bhagawaty Kalikotay ${ }^{1}$ \\ Email: bkalikote1@gmail.com
}

\section{Abstract}

There is a new public health crises threatening the world with the emergence and spread of 2019 novel coronavirus $(2019-n \mathrm{CoV})$ or the severe acute respiratory syndrome coronavirus 2 (SARS-CoV-2). There have been around 25,300,975 reported cases of coronavirus disease 2019 (COVID-2019) and 848,673 reported deaths to date (30/08/2020). Extensive literature review of publicly available information to summarize sign and symptoms as well as prevention of COVID-19 was carried out. The disease is transmitted by inhalation or contact with infected droplets and the incubation period ranges from 2 to 14 days. The symptoms are usually fever, cough, sore throat, breathlessness, fatigue, malaise among others. The disease is mild in most people; in some (usually the elderly and those with comorbidities), it may progress to pneumonia, acute respiratory distress syndrome (ARDS) and multi organ dysfunction. Many people are asymptomatic. The case fatality rate is estimated to range from 2 to $3 \%$. Diagnosis is by demonstration of the virus in respiratory secretions by special molecular tests. Common laboratory findings include elevated $C$-reactive protein $(C R P)$. Prevention entails home isolation of suspected cases and those with mild illnesses and strict infection control measures at hospitals that include contact and droplet precautions.

Key Words: community, COVID-19, Prevention and control, Review

\section{Introduction}

Corona virus disease 2019 (COVID 19) is defined as illness caused by a novel corona virus now called severe acute respiratory syndrome corona virus 2 (SARSCoV-2; formerly called 2019-nCoV), which was first identified amid an outbreak of respiratory illness cases in Wuhan City, Hubei Province, China. It was initially reported

1. Mrs Kalikotay is a Lecturer, at Tribhuvan University Institute of Medicine, Maharajgunj Nursing Campus, Kathmandu. 
to the World Health Organization (WHO) on December $31^{\text {st }}, 2019$. On January $30^{\text {th }}$, 2020, the WHO declared the COVID 19 outbreak a global health emergency. On March $11^{\text {th }}, 2020$, the WHO declared COVID 19 a global pandemic. The lungs are the most affected organs in this disease as the virus enters via the enzyme called angiotensin converting enzyme 2 (ACE2) which is mostly profuse in the type II alveolar cells of the lungs ( $\mathrm{Li}$ et al. 2020). According to WHO situation reports from its first outbreak through Wuhan, till 30th August, 2020, 213 countries are affected worldwide and a total of 25,300,974 laboratory confirmed cases of COVID 19 associated with 848,673 death, and 17,627,713 recovered. The disease is also quickly spreading in SAARC countries. In Nepal corona positive cases are 38,561, deaths 221 and recovered 20,822till 30 $0^{\text {th }}$ August, 2020 (Worldometer, 2020). The first case of COVID 19 was tested positive by real-time RT-PCR assay on $23^{\text {rd }}$ January 2020, in Nepal. The Government of Nepal issued a national lockdown on $23^{\text {rd }}$ March, 2020(News). First death due to COVID 19 was declared on $14^{\text {th }}$ May 2020. Government of Nepal extended the national lockdown until 14 June 2020 to control the spread of the COVID-19. Lockdown was end on $21^{\text {st }}$ July 2020 and implemented in selected area till now but School and university are not open till date. The virus that causes COVID-19 is thought to spread from person to person, mainly through respiratory droplets produced when an infected person coughs or sneezes. These droplets can land in the mouths or noses of people who are nearby or possibly be inhaled into the lungs. Other routes have also been implicated in the transmission of coronaviruses, such as contact with contaminated fomites and inhalation of aerosols, produced during aerosol generating procedures. Transmission of SARS-CoV-2 from asymptomatic individuals (or individuals within the incubation period) has also been described.

\section{Methods and Materials}

Extensive literature review of publicly available information focusing on COVID-19 pandemic, Signs and symptoms as well as preventive measures in community. The articles are assessed from the web of science database using key words as COVID-19, signs and symptoms, Prevention and control in community. Papers published during 2019-2020 were reviewed and summarize sign and symptoms as well as prevention of COVID-19 in community.

\section{Results and Discussion}

\section{Clinical Features}

Signs and symptoms of coronavirus disease 2019 (COVID-19) may appear two to 14 days after exposure. This time after exposure and before having symptoms is called the incubation period. Common signs and symptoms can include: Fever, Cough, Tiredness and sore throat. Early symptoms of COVID-19 may include a loss of taste 
or smell. Other symptoms can include: Shortness of breath or difficulty breathing, Muscle aches, Chills, Sore throat, Runny nose Headache, Chest pain. This list is not all inclusive. Other less common symptoms have been reported, such as rash, nausea, vomiting and diarrhea. Children have similar symptoms to adults and generally have mild illness (Mayo Clinic, 2020).

The clinical features of COVID-19 are varied, ranging from asymptomatic state to acute respiratory distress syndrome and multi organ dysfunction. In a subset of patients, by the end of the first week the disease can progress to pneumonia, respiratory failure and death (Chen et.al, 2020). The median time from onset of symptoms to dyspnea was 5 days, hospitalization 7 days and acute respiratory distress syndrome (ARDS) 8 days. The need for intensive care admission was in 25-30\% of affected patients in published series. Complications witnessed included acute lung injury, ARDS, shock and acute kidney injury. Recovery started in the 2nd or 3rd wk. The median duration of hospital stay in those who recovered was 10 days. Adverse outcomes and death are more common in the elderly and those with underlying comorbidities (50-75\% of fatal cases). Fatality rate in hospitalized adult patients ranged from 4 to $11 \%$. The overall case fatality rate is estimated to range between 2 and $3 \%$ (Wei et. al, 2020). The study shows that most common symptoms were headache $(70.3 \%)$, loss of smell $(70.2 \%)$, nasal obstruction $(67.8 \%)$, cough $(63.2 \%)$, asthenia $(63.3 \%)$, myalgia $(62.5 \%)$, rhinorrhea $(60.1 \%)$, gustatory dysfunction $(54.2 \%)$ and sore throat (52.9\%). Fever was reported by on $45.4 \%$ (Lechien, et.al. 2020). Study among 41 admitted hospital patients in china reported that Common symptoms at onset of illness were fever (40 [98\%] of 41 patients), cough (31 [76\%]), and myalgia or fatigue (18 [44\%]); less common symptoms were sputum production (11 [28\%] of 39), headache (three [8\%] of 38), haemoptysis (two [5\%] of 39), and diarrhoea (one [3\%] of 38). Dyspnoea developed in 22 (55\%) of 40 patients (median time from illness onset to dyspnoea $8 \cdot 0$ days . 26 (63\%) of 41 patients had lymphopenia. All 41 patients had pneumonia with abnormal findings on chest CT. Complications included acute respiratory distress syndrome (12 [29\%]), RNA aemia (six [15\%]), acute cardiac injury (five [12\%]) and secondary infection (four [10\%]). 13 (32\%) patients were admitted to an ICU and six (15\%) died (Hung et.al. 2020).

\section{Prevention}

Preventive measures are the current strategy to limit the spread of cases. Early screening, diagnosis, isolation, and treatment are necessary to prevent further spread. Preventive strategies are focused on the isolation of patients and careful infection control, including appropriate measures to be adopted during the diagnosis and the provision of clinical care to an infected patient. 
Isolation of confirmed or suspected cases with mild illness at home is recommended. The ventilation at home should be good with sunlight to allow for destruction of virus. Patients should be asked to wear a surgical mask and practice cough hygiene. Caregivers should be asked to wear a surgical mask when in the same room as patient and use hand hygiene every 15-20 min.

The greatest risk in COVID-19 is transmission to healthcare workers. In the SARS outbreak of 2002, 21\% of those affected were healthcare workers .While COVID-19 transmits as a droplet pathogen and is placed in Category B of infectious agents (highly pathogenic H5N1 and SARS), All contacts including healthcare workers should be monitored for development of symptoms of COVID-19. Patients can be discharged from isolation once they are afebrile for at least 3 day and have two consecutive negative molecular tests at 1 day sampling interval (Chang, et.al. 2020).

At the community level, people should be asked to avoid crowded areas and postpone non-essential travel to places with ongoing transmission. They should be asked to practice cough hygiene by coughing in sleeve/ tissue rather than hands and practice hand hygiene frequently every 15-20 min (jie et.al., 2020).

Guidelines to help protect self from contracting and transmitting SARS-CoV-2 (Coronavirus (COVID-19) Prevention, 2020)

1. Wash hands frequently and carefully: Use water and soap and rub hands for at least 20 seconds. Work the lather to wrists, between fingers, and under fingernails. It can also use an antibacterial and antiviral soap. Use hand sanitizer when cannot wash hands properly. Rewash hands several times a day, especially after touching anything, including phone or laptop.

2. Avoid touching face: SARS-CoV-2 can live on some surfaces for up to 72 hours. People can get the virus on hands if touch a surface like: gas, pump handle, cell phone a doorknob. Avoid touching any part of face or head, including mouth, nose, and eyes. Also avoid biting fingernails. This can give SARS-CoV-2 a chance to go from hands into body.

3. Stop shaking hands and hugging people-for now: Similarly, avoid touching other people. Skin-to-skin contact can transmit SARS-CoV-2 from one person to another.

4. Don't share personal items: Do not share personal items like: phones, makeup, combs. It's also important not to share eating utensils and straws. Teach children to recognize their reusable cup, straw, and other dishes for their own use only. 
5. Cover mouth and nose when cough and sneeze: SARS-CoV-2 is found in high amounts in the nose and mouth. This means it can be carried by air droplets to other people when cough, sneeze, or talk. It can also land on hard surfaces and stay there for up to 3 days. Use a tissue or sneeze into elbow to keep hands as clean as possible. Wash hands carefully after sneeze or cough, regardless.

6. Clean and disinfect surfaces: Use alcohol-based disinfectants to clean hard surfaces in home like: countertops, door handles, furniture toys, Also, clean phone, laptop, and anything else use regularly several times a day. Disinfect areas after bring groceries or packages into home. Use white vinegar or hydrogen peroxide solutions for general cleaning in between disinfecting surfaces.

7. Take physical (social) distancing seriously: If carrying the SARS-CoV-2 virus, it'll be found in high amounts in spit (sputum). This can happen even if don't have symptoms. Physical (social) distancing, also means staying home and working remotely when possible. If someone must go out for necessities, keep a distance of 6 feet $(2 \mathrm{~m})$ from other people. People can transmit the virus by speaking to someone in close contact.

8. Do not gather in groups: Being in a group or gathering makes it more likely that people will be in close contact with someone. This includes avoiding all religious places of worship, as may have to sit or stand too close to another congregant. It also includes not congregating at parks or beaches.

9. Avoid eating or drinking in public places: Now is not the time to go out to eat. This means avoiding restaurants, coffee shops, bars, and other eateries. The virus can be transmitted through food, utensils, dishes, and cups. It may also be temporarily airborne from other people in the venue. People can still get delivery or takeaway food. Choose foods that are thoroughly cooked and can be reheated. High heat (at least $132^{\circ} \mathrm{F} / 56^{\circ} \mathrm{C}$, according to one recent, not-yet-peer-reviewed lab study) helps to kill coronaviruses. This means it may be best to avoid cold foods from restaurants and all food from buffets and open salad bars.

10. Wash fresh groceries: Wash all produce under running water before eating or preparing. The Centers for Disease Control and Prevention (CDC, 2020) and the FDA do not recommend using soap, detergent, or commercial produce wash on things like fruits and vegetables. Be sure to wash hands before and after handling these items. 
11. Wear a mask: TheCDC recommends that almost everyone wears a face mask in public settings where physical distancing may be difficult, such as grocery stores. When used correctly, these masks can help prevent people who are asymptomatic or undiagnosed from transmitting SARSCoV-2 when they breathe, talk, sneeze, or cough. This, in turn, slows the transmission of the virus.

Some points to keep in mind: Wearing a mask alone will not prevent from getting a SARS-CoV-2 infection. Careful hand washing and physical distancing must also be followed.

- Wash your hands before you put on your mask.

- You can transfer the virus from your hands to the mask. If you're wearing a mask, avoid touching the front of it.

- You can also transfer the virus from the mask to your hands. Wash your hands if you touch the front of the mask.

12. Self-quarantine and Isolation if sick: Call health workers if have any_symptoms. Stay home until recover. Avoid sitting, sleeping, or eating with loved ones even if live in the same home. Wear a mask and wash hands as much as possible. If have a fever, cough and difficulty breathing, seek medical attention, but call by telephone in advance if possible and follow the directions of local health authority. National and local authorities will have the most up to date information on the situation in local area. Calling in advance will allow health care provider to quickly direct to the right health facility. This will also protect infected people and help prevent spread of viruses and other infections. Stay home and self-isolate even with minor symptoms such as cough, headache, mild fever, until recover. If need to leave house, wear a mask to avoid infecting others.

13. Keep up to date on the latest information from trusted sources: such as WHO or local and national health authorities. Local and national authorities are best placed to advise on what people in local area should be doing to protect themselves (Martinez \& Lftikhar, 2020)

Safe use of alcohol-based hand sanitizers: If using an alcohol-based hand sanitizer, make sure use and store it carefully.

- Keep alcohol-based hand sanitizers out of children's reach. Teach them how to apply the sanitizer and monitor its use.

- Apply a coin-sized amount on hands. There is no need to use a large amount of the product. 
- Avoid touching eyes, mouth and nose immediately after using an alcohol-based hand sanitizer, as it can cause irritation.

- Hand sanitizers recommended to protect against COVID-19 are alcoholbased and therefore can be flammable. Do not use before handling fire or cooking.

- Under no circumstance, drink or let children swallow an alcohol-based hand sanitizer. It can be poisonous.

- Remember that washing hands with soap and water is effective against COVID-19

\section{Conclusion}

This new virus outbreak has challenged the economic, medical and public health infrastructure of Nepal and around the glove. Wearing a mask alone will not prevent from getting a SARS-CoV-2 infection. Careful hand washing and physical distancing must also be followed.. Early screening, diagnosis, isolation, and treatment are necessary to prevent further spread .Time alone will tell how the virus will impact our lives here in Nepal.

\section{References}

CDC. (2020). Coronavirus Disease 2019 (COVID-19). Centers for Disease Control and Prevention. https:/www.cdc.gov/coronavirus/2019-ncov/faq.html

Chang, D., Xu, H., Rebaza, A., Sharma, L., \& Dela Cruz, C. S. (2020). Protecting healthcare workers from subclinical coronavirus infection. The Lancet. Respiratory Medicine, 8(3), e13. https://doi.org/10.1016/S2213-2600(20)30066-7

Chang, D., Xu, H., Rebaza, A., Sharma, L., \& Dela Cruz, C. S. (2020). Protecting healthcare workers from subclinical coronavirus infection. The Lancet. Respiratory Medicine, 8(3), e13. https://doi.org/10.1016/S2213-2600(20)30066-7

Chen, N., Zhou, M., Dong, X., Qu, J., Gong, F., Han, Y., Qiu, Y., Wang, J., Liu, Y., Wei, Y., Xia, J., Yu, T., Zhang, X., \& Zhang, L. (2020). Epidemiological and clinical characteristics of 99 cases of 2019 novel coronavirus pneumonia in Wuhan, China: A descriptive study. Lancet (London, England), 395(10223), 507-513. https://doi.org/10.1016/S0140-6736(20)30211-7

Mayo Clinic (2020). Coronavirus disease 2019 (COVID-19)—Symptoms and causes. Retrieved August 30, 2020, from https://www.mayoclinic.org/diseasesconditions/coronavirus/symptoms-causes/syc-20479963 
Huang, C., Wang, Y., Li, X., Ren, L., Zhao, J., Hu, Y., Zhang, L., Fan, G., Xu, J., Gu, X., Cheng, Z., Yu, T., Xia, J., Wei, Y., Wu, W., Xie, X., Yin, W., Li, H., Liu, M., ... Cao, B. (2020). Clinical features of patients infected with 2019 novel coronavirus in Wuhan, China. The Lancet, 395(10223), 497-506. https://doi. org/10.1016/S0140-6736(20)301835

Li, Q., Guan, X., Wu, P., Wang, X., Zhou, L., Tong, Y., Ren, R., Leung, K. S. M., Lau, E. H. Y., Wong, J. Y., Xing, X., Xiang, N., Wu, Y., Li, C., Chen, Q., Li, D., Liu, T., Zhao, J., Liu, M., ... Feng, Z. (2020). Early Transmission Dynamics in Wuhan, China, of Novel Coronavirus-Infected Pneumonia. The New England Journal of Medicine, 382(13), 1199-1207. https://doi.org/10.1056/NEJMoa2001316

Lechien, J. R., Chiesa-Estomba, C. M., Place, S., Laethem, Y. V., Cabaraux, P., Mat, Q., Huet, K., Plzak, J., Horoi, M., Hans, S., Barillari, M. R., Cammaroto, G., Fakhry, N., Martiny, D., Ayad, T., Jouffe, L., Hopkins, C., \& Saussez, S. (2020). Clinical and epidemiological characteristics of 1420 European patients with mild-to-moderate coronavirus disease 2019. Journal of Internal Medicine, 288(3), 335-344. https://doi.org/10.1111/joim.13089

Li, J., Li, J. (Justin), Xie, X., Cai, X., Huang, J., Tian, X., \& Zhu, H. (2020). Game consumption and the 2019 novel coronavirus. The Lancet. Infectious Diseases, 20(3), 275-276. https://doi.org/10.1016/S1473-3099(20)30063-3

Martinez, K. \& Lftikhar, N. (2020) Coronavirus (COVID-19) Prevention. Healthline. https://www.healthline.com/health/coronavirus-prevention

Wei, W. E., Li, Z., Chiew, C. J., Yong, S. E., Toh, M. P., \& Lee, V. J. (2020). Presymptomatic Transmission of SARS-CoV-2 - Singapore, January 23-March 16, 2020. Morbidity and Mortality Weekly Report, 69(14), 411-415. https://doi. org/10.15585/mmwr.mm6914e1

World Health Organization (2020). Situation reports. Available : https://www.who. int/emergencies/diseases/novel-coronavirus-2019/situation-reports/. Accessed 22 july 2020. 